\title{
Mentir en la vida política
}

\author{
ANA MARÍA MARTÍNEZ DE LA ESCALERA \\ UNAM, México
}

\begin{abstract}
RESUMEN. El texto «Mentir en política» aborda el papel que la mentira ha jugado en el lenguaje de la política y el lugar problemático que la Filosofía política le ha otorgado. Se escogen dos autores, Platón y Arendt, para mostrar la necesidad de incluir el discurso mentiroso como un componente esencial de la vida política de la ciudad. En breve, se trata de analizar los límites que la ciudad impone al discurso de lo político y de la política.
\end{abstract}

Es de todos conocida, al menos en su sentido general, la sentencia autoritaria platónica que excluyó de la república (politeia) ideal a los poetas ${ }^{1}$. Platón procuró que su república no fuera viciada por la presencia de narradores profesionales o mitólogos ambulantes; ciñó entonces el cerco de la censura sobre la poesía, y prohibió que se relataran o fabricaran cierto tipo de fábulas nefastas ${ }^{2}$. El argumento legitimador fue que estas rigurosas medidas sólo iban dirigidas a un propósito: evitar la fuerza disruptora del horror y del pánico míticos sobre el frágil «patriotismo» de la población. Platón consideraba que en épocas de guerra contra el extranjero, el uso indiscriminado de ciertos «nombres estremecedores» e «historias inquietantes y ambiguas»
ABSTRACT. In this paper the act of lying is seen as a necessary component of the political discourse of the polis. Plato and Arendt are examined as the representatives of a line of thought in which the political realm needs the act of lying. The actual problematic of lying in politics is debated.

conducían al debilitamiento del tejido social y la consecuente inacción de los pobladores antes que a la defensa de la sociedad. Vista así, la exclusión de los poetas indeseables fue para él un último recurso en contra de la fascinación que despertaban los antiguos relatos en una población inexperta en asuntos políticos. Que la expulsión fuera por cierto concebida como un auténtico último recurso no hizo mucho para legitimarla. Ninguna expulsión podría ocultar su dimensión violenta ni tampoco podría evitar ser considerada, probablemente, como una admisión de la derrota del primer modelo autoritario y logocéntrico del estado. El recurso a la violencia es siempre prueba de la imposibilidad de llegar a la unanimidad requerida, es 
decir, a la legitimidad indispensable para un buen funcionamiento de lo colectivo.

Comprendió luego, el filósofo, que la autoridad persuasiva del modelo republicano no podía descansar únicamente en la fuerza sagrada atribuida a lo divino; por el contrario, debía legitimarse de manera humana en el poder totalizante de la ley y en su poder instituidor y conservador (inyunción) de la realidad social. Por cierto que las leyes deben ir siempre acompañadas de la fuerza para imponer y reclamar obediencia, de lo contrario se encontrarían en una posición de virtual impotencia e inoperancia. Así, en Las Leyes, Platón se habría de preocupar por ese elemento sustancial de la ley, esa fuerza de institución de la autoridad. Se trataba de una fuerza distinta de la prohibición y de la censura que había desarrollado, en su momento, en La República. Ahora, Platón tenía en mente una fuerza que emanaba de una muy determinada estrategia retórico-política: la de la mentira. Con esto en mente, Platón decidió que el viejo mito de autoctonía y el poeta debían desaparecer para dar lugar a otro tipo de mito y otra figura alternativa de maestro de verdad (o de mentira, como veremos). Se trataba de un recurso conflictivo, como todo lo que procede del gobierno de la retoricidad de la lengua, pero inestimablemente útil. De hecho, así le llamó Platón: mentira útil o pharmakon khrésimon.

Mentira útil, medicina o veneno útil, pero también mentira bella, puesto que sólo la más amable de las ideas, la belleza (Fedro) tiene garantizado un acceso inmediato al ánimo de los hombres y de ellos al bien absoluto. La belleza fue para Platón un acompañante de la persuasión. Que este bien absoluto pueda ser conseguido a base de una ingeniería de mentiras es algo que ni el pensador griego ni los de otros tiempos y latitudes han podido presentar sin caer en una evidente paradoja, puesto que la mentira se ha considerado casi siempre un mal, incluso cuando se trata de un mal necesario. Podríamos decir, por ende, que Platón inaugura expresamente una manera de pensar las dificultades de lo político que ha corrido con suerte en Occidente $y$, aunque la historia de tal éxito no nos ocupa en este momento, sí lo hace su efecto: la generalización de la opinión de que el ejercicio y el mantenimiento del poder requiere la mentira, y que ésta no es sino una forma de artificio necesario del poder.

Hannah Arendt se pregunta a propósito de este punto de conflicto en la historia de la política y del pensamiento político lo siguiente:

Siempre se vio a las mentiras como una herramienta necesaria y justificable no sólo para la actividad de los políticos y los demagogos, sino también para la del hombre de Estado. ¿Por qué? ¿Qué significa esto para la naturaleza y la dignidad del campo político, por una parte, y para la naturaleza y la dignidad de la verdad y de la veracidad, por otra? ${ }^{3}$.

Estas interrogantes proponen con seguridad un espacio problemático transdisciplinario que vincula lo ético con lo político y lo epistemológico con lo retórico. Así: ¿Podría haber dignidad en la mendacidad? ¿Qué o quiénes saldrían perjudicados? ¿Podemos estar seguros que la verdad política se opone absolutamente a la mentira como esta última, en términos epistemológicos, se opone al error o la falsedad? A la luz de la conveniencia u oportunidad de la mendacidad política, ¿no será más bien necesaria la oposición dicotómica verdad/mentira un factor de regulación del discurso y la vida públicas?

Pese a la advertencia kantiana de que debemos tomar muy en serio cualquier desliz de lo verdadero hacia lo mentiroso, puesto que por mínimo que sea encierra un gran peligro ético-práctico, podría ser que «verdad y mentira» no fuesen valores mutuamente excluyentes, ni fuerzas complementarias, sino más bien que funcionaran como una suerte de «inyunción» reguladora. La inyunción «verdad y mentira» 
es compromiso y promesa, que funciona performativamente (Austin), y cuya fuerza originaria produce el sentido. La memoria colectiva no conserva, sin embargo, ese instante inaugural como si se tratara de un contenido, sólo recuerda la fuerza enunciativa o performativa de la que depende su valor y su éxito. Por ello se vuelve urgente considerar que la relación «verdad y mentira" posee también un contenido, aunque sea éste contingente. Habría que pensar entonces que si bien la mentira suele definirse como simulacro, falso testimonio, incluso virtualidad $y$, por lo tanto, lo otro de la verdad, en un sentido estrictamente formal o estructural; es sabido que no decir lo verdadero puede, en ciertas circunstancias, no envolver una mentira. Es posible (ilocutiva y perlocutivamente) estar en el error, engañarse sin tratar de engañar $y$, por consiguiente, sin mentir. Puede de igual manera decirse lo verdadero y estar mintiendo a los demás e incluso a uno mismo; podemos mentir con el gesto, el tono, la oportunidad o inoportunidad al decir; en fin, es posible engañar a otro aun diciendo la verdad. La performatividad de la pareja verdad y mentira es la raíz de muchos conflictos interpretativos en política y en historia.

Durante el juicio de A. Eichmann en la ciudad de Jerusalén, el fiscal trató de probar que el teniente coronel SS del III Reich mentía. Que mentía a la Corte, a los sobrevivientes que se habían dado cita en el lugar del juicio, a la historia universal y a los judíos agredidos en particular; pero no se podía mentir a sí mismo. Y que ello podía ser demostrado. El fiscal trató de hacerlo confesar; la Corte hizo lo propio: Eichmann no sólo no llegó a confesar su culpabilidad (para el caso tampoco su inocencia) respecto a la acusación de «crímenes contra la humanidad» sino que demostró no comprender exactamente a qué se referían los jueces con la noción de «responsabilidad individual». El juicio parecía tener como finalidad el comprobar que:
«Un hombre que debe responder por tantos crímenes, no podía ser más que un "tomador de decisiones", cuyo último insulto a la humanidad consistió en escudarse tras la falaz justificación de la obediencia a las órdenes» ${ }^{4}$. La Corte, al igual que la fiscalía, poseían una idea simple de la mentira; para ellos mentir era un acto intencional que demuestra hostilidad contra otros ${ }^{5}$, jamás contra uno mismo, es decir, ellos suponían que no es posible mentirse a sí mismo, ni individual ni colectivamente. Si el caso Eichmann continúa suscitando fuertes controversias no es porque existan dudas acerca de su culpabilidad en la instrumentación de la «solución final» que condujo al exterminio de gitanos, judíos, polacos y eslovenos. El problema que plantea este moderno oficial de policía en relación con la naturaleza y el estatuto de sus actividades criminales, es decir, si acaso era un monstruo, un asesino en serie como intentó mostrarlo el fiscal, o si más bien se trataba de un «engranaje», como él mismo se consideró durante el juicio, es de naturaleza político-retórica antes que moral. O si se quiere es un problema de «política de la mentira». Me refiero a que es posible compartir una mentira, obedecer a una consigna por miedo o prudencia, o por ambas razones ${ }^{6}$. Este tipo de mentira no es menos falaz que la mendacidad moral o jurídica, es simplemente diferente. Cuando los votantes uruguayos votaron a favor de la adopción de la ley de «Caducidad de la pretensión punitiva del Estado» para olvidar los crímenes políticos y la violación de los derechos humanos realizados por los militares durante la dictadura (1973-1985), lo hicieron amenazados y por miedo ${ }^{7}$, pero también porque compartían una misma «gran mentira» o «verdad particular». El gobierno republicano de Sanguinetti les había prometido el regreso del Estado de bienestar que el país había vivido desde principios del siglo $\mathrm{xx}$ hasta el año de 1962. La mayoría que votó en el referéndum por la adopción de la Ley de 
caducidad compartían con su gobierno esa promesa imposible de realizar de regreso de condiciones ya irrepetibles de la historia del país, pero además compartían con las nuevas autoridades un mismo deseo ecmnético: el olvido de la «verdad histórica». Las nuevas autoridades, como el informe del Servicio Paz y Justicia de 1989 confirmó, no querían ni justicia sancionadora ni establecimiento de una «verdad» histórica oficial: se conformaron con una ingeniería de mentiras o «verdades particulares». A diferencia de la Argentina, de Chile e incluso de Sudáfrica, los uruguayos, o si se quiere la gran mayoría de la población de electores, había resuelto aprobar la amnistía a los crímenes de las fuerzas armadas en nombre de una falaz «garantía a la estabilidad de las instituciones democráticas». La estrategia «ni justicia, ni verdad ni reparaciones» es un caso paradigmático de cómo la mentira puede llegar a adquirir proporciones históricas (historia oficial). En su momento Adolf Eichmann daría cuenta de una situación muy parecida en el III Reich: «emigración planificada», «evacuación hacia el Este», «reinstalación» y «solución final» del «material biológico» enroscaron el vocabulario de la «verdad particular» nazi sobre el cuerpo de la lengua alemana, sofocándola. Por la fuerza de las palabras el genocidio se transformaría en la única forma satisfactoria de solucionar la «cuestión judía». Pero, por cierto, ¿en qué consistía esta «cuestión» si no en las mismas estrategias de puesta en muerte, de «emigración» de la población considerada indeseable, «reinstalación» en campos de exterminio y «solución final» en los hornos crematorios, implementadas para su «control»? ¿Acaso las verdades particulares no comparten significados con la mendacidad política?

Frente a la historia de la humanidad, el crimen de Eichmann es terrible porque se trata de un crimen de un hombre común, desprovisto de hostilidad, que simplemen- te obedece llevando a cabo su tarea meticulosamente hasta la destrucción de un «otro». Como le llamó Arendt, el caso del teniente coronel es un ejemplo de la moderna «banalidad del mal». Este tipo de hombre dice lo verdadero cuando recapitula su papel de experto en transportes; no puede negarse que obedecía órdenes. Pero a la vez miente cuando expresa a la Corte que su conflicto de valores - sabía el fin que aguardaba a los transportados más allá de su escritorio- es algo íntimo, que lo exime de responsabilidad personal. Su responsabilidad no la decide él como individuo, sino la historia, las generaciones futuras que ven en él un ejemplo de moderno «asesino de escritorio». Miente no con lo que dice - pues lo que relata lo prueba con documentos-, sino cómo lo dice, a quién se dirige, de quién espera si no absolución al menos comprensión. Y la Corte por ello mismo no lo comprende. No son dos regímenes de verdad los que se enfrentan en ese entonces, son dos prácticas, dos estrategias para decir lo verdadero $\mathrm{y}$ dos formas de entender lo público: «patria» en un caso, reclamo de «verdad» en otro. En efecto, en Uruguay los grupos de madres de desaparecidos durante la dictadura ya no reclaman justicia, sólo verdad: exigen los cadáveres de sus familiares asesinados. Uno de los efectos devastadores de los estados de excepción o de represión es que la verdad queda reducida al cuerpo vacío, a la máscara de la muerte.

En general, las filosofías del siglo $\mathrm{xx}$ (salvo excepciones) han creído que la verdad es un asunto de proposiciones ${ }^{8} \mathrm{o}$ de enunciados constatativos, puesto que el análisis privilegiaba la literalidad o lo que Austin llamó la dimensión locutiva del acto verbal. A este respecto la verdad se les aparecía como lo «dicho», enunciado igual a sí mismo y sin ninguna relación con el «acto de decir» o el «acto en el cual se dice» que se vincula a la ocasión y oportunidad (kairós) de la enunciación. Como Baltasar Gracián argumentara en 
una época de crisis y oscuridad, sometida a la autoridad y al autoritarismo, ese acto es lo que hace que la verdad se parezca a sí misma y a algo muy diferente de sí. Podemos desconocer la intuición barroca de Gracián sobre la «autoridad del decir», pero entonces la verdad quedará reducida a su mínima expresión formal, considerada simplemente lo otro de lo falso, brillante pero completamente vacía (de historia). La mentira mientras tanto, como lo había presentido Platón al introducir la noción de mentira útil o bella mentira, aparece siempre más enriquecida, si se quiere, que su contraparte. El mentir es una acción pública, es una acción que tiene lugar en la ciudad y es la suma de los recursos (maniobras y estrategias) intersubjetivos producidos o también introducidos por-y-en las maneras de decir. Hoy en día, una «acción política» no remite al carácter voluntario individual del hacer, sino al carácter performativo de la relación entre verdad y mentira, carácter que no está dado solamente por la «voluntad o intención «de mentir (puesto que se puede mentir sin querer). Luego la mentira estará estrechamente vinculada con el uso del lenguaje en circunstancias determinadas. Uso que debe entenderse como un «hacer de la lengua», una operación retórico-significante irreductible a las acciones individuales, a las intenciones de los hablantes y a los contenidos proposicionales.

Un lector incauto podría entonces considerar la suposición errónea de que el «acto de mentir», en el ejemplo de Eichmann y el caso uruguayo, serían ejemplos del «objeto analítico» de la retórica, concebida como saber de lo contingente por oposición al saber necesario de la epistemología. Ese mismo lector llegaría luego a la imprudente conclusión de que mentir es lo opuesto (moral y epistemológicamente) a la verdad. Lejos de ello, es necesario enfatizar que la condición retórica de las lenguas atraviesa todo acto de lengua sin distinción, ya se trate de un uso constatativo o un uso realizativo. En ambos usos es el carácter regulador de la relación estratégica entre verdad y mentira lo que puede entenderse como elemento central de la «política de la verdad». Esta política es kairológica y precisa siempre, por tanto, de sus intérpretes. Cualquier intervención lingüística estará regida por las circunstancias que, en el pleno sentido del término, son condensaciones temporales de acción y lugar. Así, quien miente políticamente, mientras defiende su propia causa, habla además en nombre del momento del mundo que está siendo interpretado por esa circunstancia determinada. Se trata de un momento patéticamente teatral, puesto que esta oportunidad o eventualidad suprime la subjetividad sentimental del orador y la transforma en evento. El evento que allí tiene lugar contiene un momento político, estético y otro marcadamente cognocitivo, ya que la mentira no puede escapar del significado epistemológico, aunque ella misma no competa al conocimiento.

Probablemente el momento político es el más interesante. Benjamin nos hizo saber que todo momento histórico esencial es también un «momento de peligro». En la mentira «habla» el momento de peligro tanto como lo hace en el acto de la verdad, cuando ésta aparece teatralizada, es decir, exhibida en ciertas circunstancias. La verdad en política no es lo absolutamente antagónico de la mentira en política, sino su necesaria otra, su «exterior constitutivo», algo propio y a la vez distinto de sí (como dijera Baltasar Gracián). La mentira en política es así una instancia en la relación tensional y contradictoria entre la verdad y ella misma, su materialidad y su efectividad. En fin, la mentira es el «acontecimiento del mentir» según la ocasión y la oportunidad, según quién habla y quién escucha; dependiente, por lo tanto, de la posición de quien miente y las expectativas de los receptores inmediatos y mediatos. Mientras la definición clásica de mentira la hacía aparecer como una acción que com- 
portaría el uso de la lengua en ciertas condiciones, uso intencional y destinado a otros, a hacerles creer o no creer, en suma a engañarlos, mentir se acercaba a la definición de prejuicio ${ }^{9}$. Sin embargo, hemos visto que puede llegar a faltar esa intención hostil, sin que la mentira pierda violencia, es decir, que el efecto de una mentira puede no recaer sobre el receptor o interlocutor, sino quedar en cierto sentido pospuesto a una recepción ulterior de quienes ni siquiera han sido sus primeros testigos pero sí sus víctimas. En el caso de los crímenes contra la humanidad es la idea de lo humano la que resulta violentada ${ }^{10}$. De ahí la importancia de pensar la mentira como acontecimiento histórico y no mero ejemplo de subjetividad o moralidad errónea.

Con el Platón de La República y Las Leyes, el uso de la lengua para mentir se entendió de dos maneras: como dicción $y$ énfasis primero, y luego como circulación performativa del rumor. En el siglo XXI hemos aprendido a examinar la mentira a partir del grado de hostilidad contra el otro o contra la humanidad que ella pone en juego. Ello implica que hemos aprendido a fijarnos en algo más que el contenido; hemos aprendido a interrogar las técnicas de ese decir y en los efectos de la mentira a corto y a largo plazo. La mentira en este sentido, en cuanto mentira política, afecta al receptor tanto como a las formas de la memoria colectiva, a la cual modifica, destruye $u$ oculta.
Existe una vieja figura retórica que se llama catacresis. El punto central de toda catacresis es justamente el olvido. En sentido estricto la catacresis es una pura maquinaria de olvido que entra en acción «haciendo olvidar», borrando la génesis pragmática del sentido original de una expresión y volviéndola, en efecto, un cliché; integrándola y conformándola a la tradición de lo «ya dicho» y «lo que se dice». Actúa para producir el refrán, la frase hecha, la sabiduría popular, los «consejos de viejas amas», el sentido común y en especial las mentiras políticas.

La máquina de olvido que actúa en estos casos puede, sin embargo, ser desmontada, y para eso está la retórica. No hay un buen ejercicio de lectura retórica que no sepa cómo mostrar lo que se oculta detrás de ese mecanismo refinado cuya fuerza estriba en borrar que se trata de un efecto de borramiento. Mostrar, sin embargo, no significa evitar, la catacresis regresa siempre. Por cierto, su acción maquinal no es sino la de reaparecer, de reiterarse de tal forma que uno no tiene más remedio que creer que ha estado allí desde siempre, con la certeza que caracteriza cualquier hecho natural. La catacresis es nuestra segunda naturaleza y es de ella de donde la mentira política extrae su fuerza encubridora y hostil. Su arte es el de hacer olvidar, un arte de regresar sin haberse ido, de estar ahí y no dejarse ver...

\footnotetext{
Es cierto que al respecto de este pasaje de la República se han escrito demasiadas páginas para que una más sea necesaria o al menos aceptable. Empero, en la matriz discursiva que cobija la sentencia de expulsión, pocas veces tomada en consideración, se destaca el vínculo entre una política de la memoria, necesaria para la formación del individuo en tanto ciudadano, el carácter eminentemente técnico o si se prefiere «burocrático» de la misma y su relación con
}

el uso de la mentira. En estos vínculos vemos dibujarse el periplo de nuestra propia concepción del Estado moderno, sus excesos y sus peligros, hoy en día tan claros para todos nosotros. Véase Platón, República, Madrid, Gredos, $1998\left(1986,1 .^{2}\right)$.

2 Tampoco la filosofía después de Platón ha sido tolerante con la fuerza plástica del mito o con la figura del viejo maestro de verdad que antecediera al filósofo en la conquista del ánimo de la polis (Vernant). 
La intolerancia de Platón fue peculiar, sin embargo. En la República ni el poeta ni el mito fueron erradicados por completo: fueron más bien sustituidos por dos figuras menos nocivas desde la perspectiva platónica Así serán aprovechadas dos fuerzas del relato o fábula míticas: la mímesis y la pronunciatio o énfasis, ambas dirigidas por tipos o modelos ideados por los filósofos. El mito y el narrador de historias son parte fundamental de la estructura administrativa de la ciudad ideada por Platón, a la que le compete distinguir entre el rumor conveniente y el inconveniente, así como debe distinguir entre el buen o mal poeta. Los criteríos sobre los que habrá de reflexionar el filósofo son, ante todo, técnicos. Recordemos que el valor central de lo técnico se halla inmanentemente en la noción de utilidad, de lo khrésimon (lo útil, lo provechoso, lo ventajoso). Véase J. P. Vernant, Los maestros de verdad en la Grecia arcaica, Madrid, Taurus, 1981, Platón, op.cit., y Las Leyes, Madrid, Gredos, 1999.

${ }^{3}$ Arendt Hannah, «Verdad y política», en Entre el pasado y el futuro. Ocho ejercicios sobre la reflexión política, Barcelona, Península, 1996.

${ }^{4}$ R. Brauman y E. Sivan, Elogio de la desobediencia, Buenos Aires, FCE, 2000, p. 15.

s El fiscal no dejó de insistir durante el juicio en que la apelación a la obediencia por parte de Eichmann era únicamente una táctica de defensa falaz. Esta visión fue puesta en cuestión por Hannah Arendt. Brauman y Sivan, realizadores del documental Un especialista sobre material de vídeo inédito del juicio, escriben que «Eichmann va más lejos que una simple posición táctica de defensa. Pone de manifiesto las modalidades prácticas, las formas retóricas primordiales del discurso de la obediencia y de la lealtad: su tarea era técnica». Él no podía decir nada contra las directivas tomadas desde arriba. Él que no experimentaba ningún odio particular a los judíos, hubiera preferido que la matanza no tuviera lugar. Y considera haberlo demostrado sin ninguna duda trabajando con ardor en la «emigración acelerada» antes de la implementación de la «solución final». En este caso su eventual sinceridad no tiene ninguna importancia. De buen o mal grado, él organizó el saqueo de los emigrantes como después organizaría la evacuación, la reinstalación y finalmente el propio genocidio. En este contexto político la mentira no puede ser tratada simplemente como un asunto de conciencia sin atender a su dimensión táctica: la instrumentación de unanimidad o patriotismo. R. Brauman y E. Sivan, op. cit., p. 16

${ }^{6}$ En este sentido piénsese en el uso de expresiones como «justicia infinita», «guerra santa», «terrorismo» y «bioterrorismo» para organizar el sentido de los hechos en esa campaña «destinada a puerilizar los hechos» (Susan Sontag) de la administración Bush tras el 11 de septiembre. Buena parte del público norteamericano creyó y, como confirma la última reelección, sigue creyendo en ella.
${ }^{7}$ Los militares amenazaban a la población con el espectro de la batida ideológica, es decir, la repartición de la población según categorías de «peligrosidad» con arreglo al carácter «subversivo» de cada persona.

${ }^{8} \mathrm{El}$ que por lo general se crea que la verdad tiene que ver con enunciados constatativos antes que performativos no garantiza, sin embargo, que los límites entre lo constatativo y lo performativo sean, siempre claros. Austin se encargó de señalar la imposibilidad de distinguir claramente ambas dimensiones del habla. J. L. Austin, Cómo hacer cosas con palabras, Barcelona, Paidós, 1990.

${ }^{9}$ Al igual que la mentira, el prejuicio es sobre todo hostil. Como Arendt señaló, el prejuicio representa algo político en el sentido más amplio de la palabra. Si el hombre no puede vivir en sociedad sin la mentira tampoco lo hará sin prejuicios. Como el rumor platónico, los prejuicios apelan al «se dice», «se opina» que hoy literalmente plaga los medios masivos de comunicación. No son, como la mentira, fruto de la experiencia. A través de ellos la gente se reconoce, es decir, son interpelados. Ocupan un lugar fundamental en espacios sociales, donde no se mueven a partir de juicios, puesto que ni hay criterios ni reglas a partir de las cuales tomar decisiones. La libertad coexiste con los prejuicios y las mentiras. El prejuicio suele ocultar un «pedazo del pasado»: antes juicio que en su día tuvo un fundamento legítimo hoy está vacío. Imposibilitan una verdadera experiencia del presente. Mientras, la mentira oculta la memoria. Los hombres que pueden juzgar sin criterios dependen entonces de la mentira y el prejuicio, de ahí su peligrosidad. Véase, Arendt, «Introducción a la política I», en ¿Qué es la política?, Barcelona, Paidós, 1990, pp. 52-59.

10 Compete al examen de la mentira saber quién ha sido víctima de la mentira, puesto que no siempre es transparente a quién se miente ni quién resulta engañado. En su libro Eichmann en Jerusalén, Hannah Arendt se pregunta precisamente eso: ¿intentaba Eichmann engañar a la Corte cuando declaraba que durante su gestión administrativa sus funciones eran meramente «técnicas»? Con seguridad no nos engaña a los que leemos la transcripción de Arendt. Pero entonces, ¿a quién se engañaba? $Y$ durante la era del III Reich, ¿a quién engañó la «mentira burocrática»? ¿Quién vivió la separación entre la ocupación técnica (obediencia) y la interpretación política (desobediencia)? ¿Quién fue responsable del crimen contra la humanidad? $\mathrm{Ni}$ sólo los altos mandos ni tampoco todos los alemanes; como Arendt señaló, la justicia pierde sentido ante la generalización de la culpa. Exigir justicia comienza por hacer visible esa justicia, en este caso comienza por analizar el acontecimiento de una comunidad que aprendió a «mentirse a sí misma» en política. Véase H. Arendt, Eichmann en Jerusalén. Estudio sobre la banalidad del mal, Barcelona, Lumen, 1999. 